\title{
Changes in Hematological, Clinical and Laboratory Parameters for Children with COVID-19: Single-Center Experience
}

\author{
Mahasen Saleh ${ }^{1}$ \\ Amani Alkofide' \\ Anfal Alshammari ${ }^{1}$ \\ Khawar Siddiqui' \\ Tarek Owaidah ${ }^{2,3}$ \\ 'Department of Pediatric Hematology \\ Oncology, King Faisal Specialist Hospital \\ and Research Center, Riyadh, II533, \\ Kingdom of Saudi Arabia; ${ }^{2}$ Department of \\ Pathology and Laboratory Medicine, King \\ Faisal Specialist Hospital and Research \\ Center, Riyadh, I I I I, Kingdom of Saudi \\ Arabia; ${ }^{3}$ Department of Pathology, \\ Alfaisal University, Riyadh, II533, \\ Kingdom of Saudi Arabia
}

Background: COVID-19 wreaked havoc on the healthcare system, with more than 36 million cases reported globally. Although the pediatric population makes up a lesser proportion of total COVID-19 patients than adults, the clinical status, age and comorbidities warrant identifying possible prognostic factors associated with disease severity in this group. The current study aimed to explore the incidence of thrombosis, overall outcome, and different hematological and coagulation markers in children with COVID-19.

Methods: This is a single-center prospective study of 43 patients (age $<14$ years) with confirmed COVID-19 diagnosis recruited from April to August 2020. Data for clinical presentation were collected and analyzed. The samples were tested for different hematological and coagulation markers.

Results: Twenty-nine (67.4\%) were symptomatic at presentation, with fever being the most common symptom $(\mathrm{n}=23,53.5 \%)$, followed by respiratory $(\mathrm{n}=5,11.6 \%)$ and gastrointestinal symptoms $(n=3,7 \%)$. Co-morbid conditions were recorded in $26(60.5 \%)$ patients, with malignancy being the commonest $(n=9,20.9 \%)$. In this cohort of patients with age $<14$ years, hypertension, respiratory symptoms and $\mathrm{ABO}$ group-A were significantly associated with pediatric intensive care unit (PICU) admission during the course of treatment. Patients with elevated FVIII and fibrinogen levels at presentation were more likely to have an extended length of hospital stay $(\operatorname{LOS})(P$-value $=0.036$ and 0.032 respectively $)$. No thrombotic event was observed in our cohort. D-dimer values were higher (above $0.5 \mu \mathrm{g} / \mathrm{mL}$ ) in $24(55.8 \%)$ patients at admission. We found an association between high D-dimer and PICU admission and LOS.

Conclusion: Although we did not observe thrombosis in our cohort, serial measurements of D-dimer and elevated FVIII bear a prognostic value in predicting the need for critical care in children with COVID-19. Further studies with larger sample size can aid in the establishment of prognostic factors for the pediatric COVID-19 population.

Keywords: COVID-19, children, hematological and coagulation markers

\section{Introduction}

A novel $\beta$ coronavirus, $2019-\mathrm{nCoV}$ or SARS-CoV-2 infection leading to Coronavirus disease-19 (COVID-19), emerged in Wuhan, China, in December 2019. ${ }^{1}$ Despite exceptional patient care and healthcare technology, the alarming mortality rate demands research to identify prognostic factors associated with COVID-19. The clinical severity of the disease is variable, from mild respiratory symptoms to severe cases requiring intensive care. The virus has caused more than 2 million deaths globally. ${ }^{2}$
Correspondence: Tarek Owaidah

Email towaidah@kfshrc.edu.sa 
One of the various manifestations of COVID-19 is hypercoagulability. ${ }^{3}$ There are no clear criteria to predict the cases that will progress to severe clinical symptoms that may require intensive care. Venous and arterial thrombosis has been reported in COVID-19, with the involvement of microcirculatory systems. ${ }^{4}$ Different mechanisms induced by thrombosis coupled with intra-alveolar fibrin deposition can lead to lethal respiratory failure.$^{5-7}$ Several hematological markers may aid in optimizing treatment at earlier stages and may predict prognosis in real-time. ${ }^{8,9}$ Changes in coagulation test, including elevated D-dimers, had been reported in (3.7-68\%) and fibrinogen in $(5.7 \%$ in mild and $19.1 \%$ severe cases) and have been shown to be reliable predictors of poor outcome in hospitalized COVID-19 adult patients. ${ }^{8,10}$

In the general population, venous thrombosis occurs at an annual incidence of about $1 / 1000$ in adults ${ }^{11}$ and $0.07-$ $0.14 / 10,000$ in children. In hospitalized children, VTE occurs in $5.3 / 10,000{ }^{12}$ In children $<13$ years with COVID-19, the rate of VTE is reported to be $1.3 \%{ }^{13}$ In a larger cohort of 180 pediatric patients, although a $2 \%$ mortality with Covid-19 was reported, yet no incidence of VTE was found. ${ }^{14}$ Data regarding the prognostic factors in the pediatric age group are scarce. D-dimers, a probable biomarker of disease severity and mortality in COVID-19, have not been tested regularly in pediatric patients. While several hematological societies have published recommendations for the anticoagulation of hospitalized symptomatic adult patients with COVID-19, ${ }^{15}$ such guidelines, however, cannot be established for pediatric patients due to a dearth of data in that population.

The current study aimed to evaluate the changes in hematological and coagulation markers, such as $\mathrm{CBC}$, different WBCs, D-dimer, Fibrinogen (FIB), Antithrombin (AT), Protein C (PC), Protein S (PS) von Willebrand factor antigen (vWF Ag), and factor VIII as prognostic factors in pediatric patients with COVID-19.

\section{Methods}

\section{Patient Population}

From April to August 2020, a total of 43 children (age $<14$ years) were hospitalized with COVID-19 related symptoms. The study complied with the Declaration of Helsinki, and informed consent was obtained from the patients' guardians after appropriate approval by the Institutional Review Board of the hospital. In this prospective study, patients' demographics, details on symptoms,
COVID-19 stage, sequential hematological profile, treatment, and outcome were recorded throughout their stay in the hospital. Inclusion criteria were all PCR confirmed COVID-19 patients $<14$ years with the need for inhospital treatment.

Excluded were patients transferred from other hospitals and patients already admitted or intubated at admission; outpatient patients and those with negative COVID-19 testing were excluded from data analysis.

\section{Blood Sample Collection}

Blood Samples comprising $10 \mathrm{cc}$ of EDTA, $10 \mathrm{cc}$ of Citrated blood (at 3.2\%), and $5 \mathrm{cc}$ sodium heparin were collected at admission, 3rd day, 7th day, and 14th day for those who stayed for up to 14 days. $\mathrm{CBC}$ and complete 5 parts differential were tested from the EDTA samples using an automated SYSMEX XN-10 instrument (Sysmex Corporation, Kobe, Japan). Serum creatinine and $\mathrm{C}$ reactive protein were measured using an automated chemistry analyzer COBAS 601 (Roche Diagnostics, Basel, Switzerland). ABO blood grouping was carried out via Diamed Gel card (Changsha Yingtai Instrument Co., Ltd).

The samples for the coagulation tests were centrifuged within two hours and aliquoted for testing different coagulation markers, including prothrombin time (PT), international normalization ratio (INR), activated thromboplastin time (APTT), D-dimer, FIB, AT, PC, PS, vWF $\mathrm{Ag}$, and FVIII using STAR Max $^{\circledR}$ (Diagnostica Stago, Marseille, France).

\section{COVID-19 Clinical Stages}

To explore the correlation between disease severity and coagulation markers, we used a hospital-based clinical staging system for COVID-19 to assess disease severity. The system divides patients into stages $\mathrm{A}$ to $\mathrm{E}$, as shown in Table 1.

\section{Statistical Analysis}

After performing quality checks on the dataset, descriptive statistics were calculated. Measures of central tendency and dispersion for continuous variables are provided as the mean and standard deviation for normally distributed data, while median with range for data that did not conform to normality assumptions and categorical variables as number and percentage. To test the significance of association between categorical variables, we used the Chi-square test or Fisher's exact. Independent-samples Mann- 
Table I Hospital-Based Clinical Staging System for COVID-19 to Assess Disease Severity

\begin{tabular}{|l|l|l|}
\hline Stage & $\begin{array}{l}\text { Clinical } \\
\text { Presentation }\end{array}$ & Characteristic Features \\
\hline Stage A & Asymptomatic & Patients with no signs or symptoms of infection \\
\hline Stage B & Mild Infection & $\begin{array}{l}\text { Upper respiratory tract infection symptoms and other mild symptoms (including fever and gastrointestinal } \\
\text { symptoms) without evidence of pneumonia }\end{array}$ \\
\hline Stage C & $\begin{array}{l}\text { Moderate } \\
\text { Infection }\end{array}$ & $\begin{array}{l}\text { Patients with hypoxia with oxygen saturation less than 93\% at rest or presence of pneumonia not requiring } \\
\text { ICU admission }\end{array}$ \\
\hline Stage D & Severe Infection & $\begin{array}{l}\text { Pneumonia requiring ICU admission or any of the following: } \\
\text { I. Respiratory rate of } 30 \text { breaths/min } \\
\text { 2. Arterial oxygen partial pressure to fractional inspiratory oxygen ratio (PaO2/FiO2) less than 300 } \\
\text { 3. More than 50\% lung involvement on imaging within 24-48 hours } \\
\text { 4. Critical respiratory failure requiring mechanical ventilation, septic shock, or multi-organ dysfunction }\end{array}$ \\
\hline
\end{tabular}

Whitney $U$-Test and Kruskal-Wallis Test were used to test the significance of the difference between two and more than two categories of continuous variables. Correlation between various continuous variables was calculated using Spearman correlation coefficient. A p-value of less than 0.05 was considered to be statistically significant. All data analysis was performed using SPSS version v23 (IBM Corp, Armonk NY, USA).

\section{Results}

\section{Demography}

Our cohort consisted of 43 children with confirmed COVID-19 diagnoses. The male-to-female ratio was $1: 1.3$ with a median age of 5.8 years (range " $r$ " $=4$ months - 13.3 years). Twenty-nine $(67.4 \%)$ were symptomatic at presentation, with fever being the most common symptom $(n=23,53.5 \%)$, followed by respiratory $(n=5$, $11.6 \%)$ and gastrointestinal symptoms $(n=3,7 \%)$. Comorbid conditions were recorded in $26(60.5 \%)$ patients, with malignancy being the commonest $(n=9,20.9 \%)$. The COVID-19 staging was done for all the patients using standard COVID-19 staging, as shown in Table $1 .^{16-19}$ COVID-19 stage B was the most common stage at the time of presentation $(n=27,62.8 \%)$, followed by stage A $(n=14,32.6 \%)$.

\section{Length of Stay at the Hospital and Pediatric Intensive Care Unit (PICU)}

The median duration of hospital stay was nine days ( $r=1-$ 48). PICU admission rate was $11.6 \%(\mathrm{n}=5)$, with an average time to transfer to PICU from the pediatric care wards of $2.6 \pm 3.2$ days ( $r=0-7$ days). Patients' demographics and clinical characteristics associated with PICU admission are presented in Table 2, showing that younger patients, hypertension, respiratory symptoms, and $\mathrm{ABO}$ group-A were significantly associated with PICU admission during treatment. Of the 41 patients with known $\mathrm{ABO}$ groups, no significant association between the COVID-19 stage and ABO groups was observed at presentation $(P-$ value $=0.638$ ). Overall, the average length of stay (ALOS) was significantly higher in patients with COVID-19 stage B (9.8 days, $\mathrm{r}=2-23)$ as compared to Stage A (6.8 days, $\mathrm{r}=$ 1-12, $P$-value=0.046). Contrarily, ALOS was not significantly different across different $\mathrm{ABO}$ groups $(P$-value $=0.374)$. There is no association between stage $\mathrm{B}$ and ALOS $(P$-value $=0.081)$. Patients with elevated FVIII, fibrinogen, and D-dimer at presentation were more likely to have an extended length of hospital stay ( $P$-value $=0.036,0.032$, and 0.034 , respectively).

\section{Risk Factors and Associations with Hospital Stay and PICU Admission}

None of our patients experienced any thrombotic event during the admission period, even though D-dimer values were higher (above $0.5 \mu \mathrm{g} / \mathrm{mL}$ ) in $24(55.8 \%$ ) patients at admission (Figure 1), with 4 out of those 24 (16.7\%) requiring PICU admission. An associative trend was observed between high D-dimer values and COVID19 stage at admission, with $75 \%$ (18 of 27) of stage $\mathrm{B}$ patients having high $\mathrm{D}$-dimer $(P$-value $=0.081)$. There was also a trend for patients with higher D-dimer at admission to have an ICU visit (4 of 24, 16.7\%) 
Table 2 Demographics and Clinical Parameters of COVID-19-Infected Patients

\begin{tabular}{|c|c|c|c|c|}
\hline Parameters & All Cases $(n=43)$ & No ICU Visit $(n=38)$ & With ICU Visit (n=5) & P-value \\
\hline \multicolumn{5}{|l|}{ Demographic and clinical } \\
\hline Age (years) & $5.8(0.04-13.3)$ & $5.9(0.06-13.32)$ & $\mathrm{I} .4(0.04-7.12)$ & 0.04 \\
\hline Gender (female/male) & $24 / 19$ & $20 / 18$ (52.6\%) & 4/I (80.0\%) & 0.363 \\
\hline BMI & $15.7 \pm 2.9$ & $15.8 \pm 2.9$ & $15.0 \pm 2.8$ & 0.58 \\
\hline Comorbidities (positive/negative) & $26 / 17$ (60.5\%) & $22 / 16(57.9 \%)$ & $4 / I(80.0 \%)$ & 0.633 \\
\hline Hypertension & $2 / 4 \mathrm{I}(4.7 \%)$ & $0 / 38(0 \%)$ & $2 / 3(40.0 \%)$ & 0.011 \\
\hline Diabetes & $1 / 42(2.3 \%)$ & $\mathrm{I} / 37(2.6 \%)$ & $0 / 5(0 \%)$ & 1.000 \\
\hline Bleeding & $0 / 43(0 \%)$ & $0 / 38(0 \%)$ & $0 / 5(0 \%)$ & - \\
\hline Previous VTE & $0 / 43(0 \%)$ & $0 / 38(0 \%)$ & $0 / 5(0 \%)$ & - \\
\hline Malignancy & $9 / 34(20.9 \%)$ & $8 / 30(21.1 \%)$ & $\mathrm{I} / 4(20.0 \%)$ & 1.000 \\
\hline Hyperlipidemia & $1 / 42(2.3 \%)$ & I/37 (2.6\%) & $0 / 5(0 \%)$ & 1.000 \\
\hline Stem Cell Transplantation & $6 / 37(14.0 \%)$ & $4 / 34$ (10.5\%) & $2 / 3(40 \%)$ & 0.135 \\
\hline Symptoms (positive/negative) & $27 / 16(62.8 \%)$ & $23 / 15(60.5 \%)$ & $4 / I(80.0 \%)$ & 0.635 \\
\hline Fever & $23 / 20(53.5 \%)$ & $19 / 19(50.0 \%)$ & $4 / I(80.0 \%)$ & 0.351 \\
\hline Respiratory & $5 / 38(11.6 \%)$ & $2 / 36(5.3 \%)$ & $3 / 2(60.0 \%)$ & 0.008 \\
\hline GIT related & $3 / 40(7.0 \%)$ & $3 / 35(7.9 \%)$ & $0 / 5(0 \%)$ & 1.000 \\
\hline COVID-19 Stage & & & & 0.072 \\
\hline Stage A & $14(32.6 \%)$ & $14(36.8 \%)$ & $0(0 \%)$ & \\
\hline Stage B & 27 (62.8\%) & $23(60.5 \%)$ & $4(80 \%)$ & \\
\hline Stage C & I (2.3\%) & $0(0 \%)$ & I (20\%) & \\
\hline Stage D & I (2.3\%) & I (2.6\%) & $0(0 \%)$ & \\
\hline Stage E & $0(0 \%)$ & $0(0 \%)$ & $0(0 \%)$ & \\
\hline ABO groups $(n=4 I)$ & & & & 0.049 \\
\hline A & $13(31.7 \%)$ & $9(25.0 \%)$ & $4(80.0 \%)$ & \\
\hline$A B$ & $2(4.9 \%)$ & $2(5.6 \%)$ & $0(0 \%)$ & \\
\hline B & $8(19.5 \%)$ & 7 (19.4\%) & I (20.0\%) & \\
\hline O & 18 (43.9\%) & I8 (50.0\%) & $0(0 \%)$ & \\
\hline
\end{tabular}

Notes: The variable BMI was normally distributed while age followed a non-normal distribution. Data are presented as mean \pm standard deviation for normally distributed and median (minimum-maximum) for non-normally distributed variable.

Abbreviations: GIT, gastrointestinal tract; DIC, disseminated intravascular coagulopathy; INR, international normalized ratio; PT, prothrombin time; HCT, hematopoietic cell transplant.

compared to their counterparts ( 1 of $19,5.3 \%, P$-value $=0.363$ ). More than half of our patients continued to have high D-dimer throughout the course of their admission (Supplementary Table 1). No significant change in neutrophil, lymphocyte count, C-Reactive protein levels, or hemoglobin was observed during the hospital stay, as shown in Supplementary Table 2.

\section{VTE Prophylaxis}

VTE with Enoxaparin $1 \mathrm{mg} / \mathrm{kg}$ daily was given to only six (14\%) patients; two were PICU admission. Clinical profile and symptoms observed at admission, day 3, 7, and 14 are presented in Supplementary Table 1, while sequential laboratory profile is detailed in Supplementary Table 2. Only one patient with malignancy was positive for Lupus anticoagulant; was put on VTE prophylaxis $(1 \mathrm{mg} / \mathrm{kg})$ for
11 days and discharged afterward without any remarkable event.

\section{PICU Support Prerequisites}

The median PICU length of stay was 3 days $(r=2-11)$, where one patient required intubation and ventilation; however, the patient recovered well. All patients were discharged from the hospital in a generally good condition. There was no association between age at diagnosis, BMI, D-dimer, and hypertension at presentation. The median length of stay at the hospital was not significantly different for patients with D-dimer higher than $0.5 \mu \mathrm{g} / \mathrm{mL}$ (median 9 days, $r=1-48$ days) compared to their counterparts (median 8 days, $r=2-20$ days, $P$-value $=0.094)$. There was a weak positive correlation between $\mathrm{D}$-dimer at presentation and hospital stay (Spearman's rho 0.325, $P$-value=0.034). 


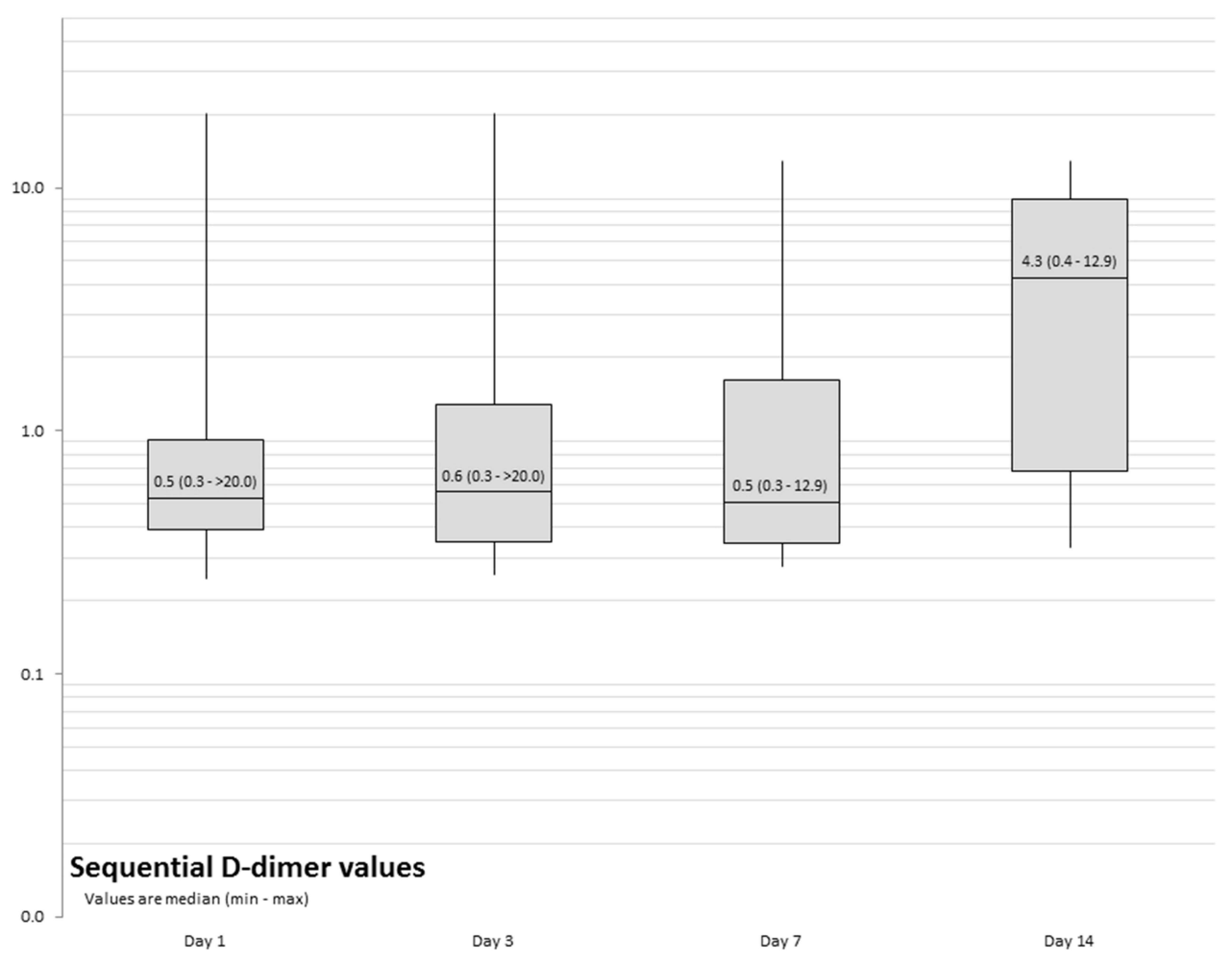

Figure I Sequential D-dimer values.

Five patients out of 43 patients needed PICU support. Four $(80 \%)$ had high D-dimer compared to only one with normal D-dimer $(P$-value $=0.363)$. The average length of stay at the PICU for these four patients was $6.5 \pm 4.7$ days $(r=2-11)$, while it was two days for the one with normal D-dimer $(\leq 0.5 \mu \mathrm{g} / \mathrm{mL})$. A weak association was found between COVID-19 stage at presentation and the level of D-dimer $(P$-value $=0.081)$.

\section{Laboratory and Coagulation Factors}

WBC showed an increasing trend from the day of admission (7.5 \pm 4.3$)$ to Day $14(8.1 \pm 4.7)$ at admission, whereas $\mathrm{HgB}$ was declining $(111.7 \pm 19.1$ vs $76 \pm 36.1)$. No such trend was observed in platelet, neutrophils and lymphocytes. The mean and median of other laboratory parameters are presented in Supplementary Table 2.

No statistically significant correlation was found for low PC and PS or high $\mathrm{vWF}$ Ag at presentation with respect to D-dimer or outcome (Table 3).

Median D-dimer values at admission were found to be higher in patients with malignant disorders $(0.78 \mu \mathrm{g} / \mathrm{mL}$, $\mathrm{n}=9)$ compared to those with non-malignant diseases $(0.52$ $\mu \mathrm{g} / \mathrm{mL}, \mathrm{n}=34)$; however, the difference was not found to be statistically significant $(P$-value $=0.369)$. No significant correlation or association was noted between D-dimer and FVIII at admission (P-values 0.393 and 0.262).

\section{Discussion}

COVID-19 has wreaked havoc on the healthcare system and caused over one million deaths globally, which indicates disease severity and a lack of prognostic factors to estimate the patient outcomes and plan treatment strategies. Thrombosis had been linked to disease severity in the adult population, for which management guidelines are released by multiple hematology organizations. ${ }^{20,21}$ Children appear to account for a much lesser proportion of total COVID-19 infected patients. Various studies have reported a low incidence of thromboembolic complications in children with COVID-19. In a study containing 91 pediatric patients, one developed VTE. ${ }^{22}$ None of our patients experienced any thrombotic event, even though only six (14\%) received VTE prophylaxis. It is paramount to unfold prognostic biomarkers in children with COVID19 as this population is unique due to its potential vulnerability, younger age, co-existing and co-morbid conditions with a lack of data to guide and determine therapeutic 
Table 3 Length of Stay by Coagulation Biomarkers at Admission

\begin{tabular}{|c|c|c|c|c|c|}
\hline \multirow[t]{2}{*}{ At Presentation } & \multicolumn{4}{|c|}{ Hospital Stay } & \multirow[t]{2}{*}{ P-value } \\
\hline & < 3 Days & 3-7 Days & 7-14 Days & $\begin{array}{l}14 \text { and } \\
\text { Above }\end{array}$ & \\
\hline Protein C & & & & & 0.802 \\
\hline Low & $0(0 \%)$ & I (I4.3\%) & I (4.5\%) & $0(0 \%)$ & \\
\hline Normal & $3(100 \%)$ & $6(85.7 \%)$ & 20 (90.9\%) & $5(100 \%)$ & \\
\hline Protein S & & & & & 1.000 \\
\hline Low & - & - & - & - & \\
\hline Normal & $3(100 \%)$ & 7 (100\%) & 21 (95.5\%) & $5(100 \%))$ & \\
\hline vW Ag & & & & & 0.388 \\
\hline Low & - & - & - & - & \\
\hline Normal & $3(100 \%)$ & $4(57.1 \%)$ & $15(68.2 \%)$ & $2(40 \%)$ & \\
\hline High & $0(0 \%)$ & $3(42.9 \%)$ & 7 (3I.8\%) & $3(60 \%)$ & \\
\hline FVIII & & & & & 0.036 \\
\hline Low & - & - & - & - & \\
\hline Normal & $3(100 \%)$ & 6 (85.7\%) & $18(81.8 \%)$ & I (20\%) & \\
\hline High & $0(0 \%)$ & I (I4.3\%) & $4(18.2 \%)$ & $4(80.0 \%)$ & \\
\hline Fibrinogen & & & & & 0.151 \\
\hline Low $(n=5)$ & $0(0 \%)$ & $0(0 \%)$ & $5(23.8 \%)$ & $0(0 \%)$ & \\
\hline Normal $(n=25)$ & $3(100 \%)$ & $7(100 \%)$ & 12 (57.1\%) & $3(50 \%)$ & \\
\hline High $(n=7)$ & $0(0 \%)$ & $0(0 \%)$ & 4 (19.0\%) & $3(50 \%)$ & \\
\hline
\end{tabular}

measures and prognostic factors. Dong et al, in an epidemiological study, reported 34.1\% laboratory-confirmed and $65.9 \%$ suspected pediatric patients of COVID-19. ${ }^{23}$

Elevated D-dimer of $>1 \mu \mathrm{g} / \mathrm{mL}$ is associated with poor prognosis and mortality in adult COVID-19 patients. $^{24}$ Our data demonstrate that higher D-dimer can predict disease severity leading to longer hospitalization and PICU stay, which is in contrast to Del Borrello et al prospective study on 35 pediatric COVID-19 patients, where he found D-dimer values apparently do not distinguish mildly affected COVID-19 patients from more severely affected cases. $^{25}$

D-dimer values were higher in $55.8 \%$ of patients at admission. A weak positive correlation was found between D-dimer at presentation and hospital stay at an individual level in our cohort. No significant association between high D-dimer at admission with COVID-19 stages or risk factors was found in our study. Tang et $\mathrm{al}^{20}$ had reported an overall mortality of $11.5 \%$, significantly higher D-dimer and fibrin degradation product (FDP) levels, longer prothrombin and activated partial thromboplastin times in non-survivals compared to survivors on admission. ${ }^{7}$ This discrepancy in results indicates that the prognostic factors in COVID-19 are different between adult and pediatric populations, warranting further investigation.

Zou et $\mathrm{al}^{26}$ have also reported a significant increase in fibrinogen levels in 5.7\% of COVID-19 patients with mild disease and $19.1 \%$ patients with severe disease. In critically ill COIVD-19 patients, a prothrombotic diathesis has been reported with significantly higher fibrinogen levels. ${ }^{27}$ Our study findings are similar to the reported data whereby the fibrinogen levels increase with time in admitted patients.

The attributable risk for severe disease from COVID19 in children is challenging to discern. Feldstein et al reported that $92 \%$ of patients aged $<1-20$ years had positive biomarkers like elevated erythrocyte sedimentation rate or C-reactive protein level, lymphocytopenia, neutrophilia, elevated ferritin level, hypoalbuminemia, elevated alanine aminotransferase level, anemia, thrombocytopenia, and an elevated D-dimer level indicating inflammation. ${ }^{14}$ Our reported results are in concordance with the study of Feldstein et al.

None of the pediatric subjects included in this study died, suggesting minimal disease mortality among this age group. The susceptibility of children for being infected 
with SARS-CoV-2 is similar to those of adults; however, the disease is less severe among children, and thus mortality is also low. ${ }^{28-30}$ Various immunological hypotheses have been put forward to support these findings. Firstly, the angiotensin-converting enzyme 2 (ACE2) receptor, a binding site for SARS-CoV-2, is lower in children than adults. $^{31}$ Secondly, children usually have few comorbidities. $^{32,33}$ However, the morbidity associated with COVID-19 is significantly higher in populations with a high prevalence of childhood obesity. ${ }^{34}$ These findings suggest that the risk of being infected is similar for children and adults; however, children are less prone to severe disease outcomes.

Another similarity between adult and pediatric infected patients admitted to PICU is the high percentage of blood group A as previously reported by Yaylac et al; a similar trend was observed in our study. ${ }^{35}$ Additionally, comorbidities affected the PICU admission and length of stay significantly. In our cohort, co-morbid conditions were recorded in $26(60.5 \%)$ patients, with malignancy being the commonest $(20.9 \%)$. One of the limitations of our study was the small sample size presenting some weak associations.

\section{Conclusion}

We observed a very low incidence of VTE in children with COVID-19, with a weak association between D-dimer and COVID-19 stage at presentation, but no significant correlation of natural anticoagulants with PC, PS, and AT. We suggest that serial measurements of D-dimer and FVIII bear a prognostic value in predicting the need for critical care in children with COVID-19 patients. Further studies with a larger sample size can aid in the establishment of prognostic factors in this patient group.

\section{Data Sharing Statement}

Furnished upon request to the corresponding author.

\section{Ethics Approval and Consent to Participate}

The study was approved by the Institutional Review Board of King Faisal Specialist Hospital and Research Center, Kingdom of Saudi Arabia, under approval \# RAC KFSHRC (2201086). Informed consent was obtained from the research subjects' guardians prior to study commencement.

\section{Consent for Publication}

All authors consent to publication.

\section{Author Contributions}

All authors made a significant contribution to the work reported, whether that is in the conception, study design, execution, acquisition of data, analysis and interpretation, or in all these areas; took part in drafting, revising or critically reviewing the article; gave final approval of the version to be published; have agreed on the journal to which the article has been submitted; and agree to be accountable for all aspects of the work.

\section{Funding}

KACST (408-34).

\section{Disclosure}

The authors report no conflicts of interest in this work.

\section{References}

1. Zhou P, Yang X-L, Wang X-G, et al. A pneumonia outbreak associated with a new coronavirus of probable bat origin. Nature. 2020;579(7798):270-273. doi:10.1038/s41586-020-2012-7

2. Worldometers. COVID-19 coronavirus pandemic; 2021 [cited July 3, 2021]. Available from: https://www.worldometers.info/coronavirus/? utm_campaign=homeAdvegas 1?. Accessed August 18, 2021.

3. Becker RC. COVID-19 update: Covid-19-associated coagulopathy. J Thromb Thrombolysis. 2020;50(1):54-67. doi:10.1007/s11239-02002134-3

4. Grewal S, Harjo B, Aykut G, et al. Case report: sublingual microcirculatory alterations in a Covid-19 patient with subcutaneous emphysema, venous thrombosis, and pneumomediastinum. Front Med. 2020;7:624695. doi:10.3389/fmed.2020.624695

5. Helms J, Tacquard C, Severac F, et al. High risk of thrombosis in patients with severe SARS-CoV-2 infection: a multicenter prospective cohort study. Intensive Care Med. 2020;46(6):1089-1098.

6. Iba T, Levy JH, Levi M, Connors JM, Thachil J. Coagulopathy of coronavirus disease 2019. Crit Care Med. 2020;48(9):1358-1364. doi:10.1097/CCM.0000000000004458

7. Tang N, Li D, Wang X, Sun Z. Abnormal coagulation parameters are associated with poor prognosis in patients with novel coronavirus pneumonia. J Thromb Haemost. 2020;18(4):844-847. doi:10.1111/ jth.14768

8. Yao Y, Cao J, Wang Q, et al. D-dimer as a biomarker for disease severity and mortality in COVID-19 patients: a case control study. J Intensive Care. 2020;8(1):1-11. doi:10.1186/s40560-020-00466-z

9. Zhang L, Yan X, Fan Q, et al. D-dimer levels on admission to predict in-hospital mortality in patients with Covid-19. J Thromb Haemost. 2020;18(6):1324-1329. doi:10.1111/jth.14859

10. Eljilany I, Elzouki A-N. D-dimer, fibrinogen, and IL-6 in COVID-19 patients with suspected venous thromboembolism: a narrative review. Vasc Health Risk Manag. 2020;16:455. doi:10.2147/VHRM.S280962

11. Cushman M, editor. Epidemiology and risk factors for venous thrombosis. Semin Hematol. 2007;44(2):62-69. Elsevier.

12. Celkan T, Dikme G. Thrombosis in children: which test to whom, when and how much necessary? Turk Arch Pediatr. 2018;53(1):1. doi:10.5152/TurkPediatriArs.2018.2586 
13. Goldenberg NA, Sochet A, Albisetti M, et al. Consensus-based clinical recommendations and research priorities for anticoagulant thromboprophylaxis in children hospitalized for COVID-19-related illness. J Thromb Haemost. 2020;18(11):3099-3105. doi:10.1111/ jth. 15073

14. Feldstein LR, Rose EB, Horwitz SM, et al. Multisystem inflammatory syndrome in US children and adolescents. $N$ Engl J Med. 2020;383(4):334-346. doi:10.1056/NEJMoa2021680

15. Loi M, Branchford B, Kim J, Self C, Nuss R. COVID-19 anticoagulation recommendations in children. Pediatr Blood Cancer. 2020;67(9):e28485. doi:10.1002/pbc.28485

16. Thachil J, Cushman M, Srivastava A. A proposal for staging COVID-19 coagulopathy. Res Pract Thromb Haemost. 2020;4 (5):731-736. doi:10.1002/rth2.12372

17. Fan L, Liu S. CT and COVID-19: Chinese experience and recommendations concerning detection, staging and follow-up. Eur Radiol. 2020;30(9):5214-5216.

18. Marchandot B, Trimaille A, Curtiaud A, et al. Staging severity of COVID-19 according to hemostatic abnormalities (CAHA score). Thromb Haemost. 2020;120(12):1716-1719.

19. Cordon-Cardo C, Pujadas E, Wajnberg A, et al. COVID-19: staging of a new disease. Cancer Cell. 2020;38(5):594-597. doi:10.1016/j. ccell.2020.10.006

20. Thachil J, Tang N, Gando S, et al. ISTH interim guidance on recognition and management of coagulopathy in COVID-19. J Thromb Haemost. 2020;18(5):1023-1026. doi:10.1111/jth.14810

21. Iba T, Levy JH, Levi M, Thachil J. Coagulopathy in COVID-19. J Thromb Haemost. 2020;18(9):2103-2109. doi:10.1111/jth.14975

22. Caro-Dominguez P, Shelmerdine SC, Toso S, et al. Thoracic imaging of coronavirus disease 2019 (COVID-19) in children: a series of 91 cases. Pediatr Radiol. 2020;50(10):1354-1368. doi:10.1007/s00247020-04747-5

23. Dong Y, Mo X, Hu Y, et al. Epidemiology of COVID-19 among children in China. Pediatrics. 2020;145(6):e20200702. doi:10.1542/ peds.2020-0702

24. Ogimi C, Englund JA, Bradford MC, Qin X, Boeckh M, Waghmare A. Characteristics and outcomes of coronavirus infection in children: the role of viral factors and an immunocompromised state. J Pediatric Infect Dis Soc. 2019;8(1):21-28. doi:10.1093/ jpids/pix093
25. Del Borrello G, Giraudo I, Bondone C, et al. SARS-CoV-2 associated coagulopathy and thromboembolism prophylaxis in children: a Single Centre Observational Study. J Thromb Haemost. 2021;19 (2):522-530.

26. Zou Y, Guo H, Zhang Y, et al. Analysis of coagulation parameters in patients with COVID-19 in Shanghai, China. Biosci Trends. 2020;14 (4):285-289. doi:10.5582/bst.2020.03086

27. Thachil J, Agarwal S. Understanding the COVID-19 coagulopathy spectrum. Anaesthesia. 2020;75(11):1432-1436. doi:10.1111/ anae. 15141

28. Zimmermann P, Curtis N. COVID-19 in children, pregnancy and neonates: a review of epidemiologic and clinical features. Pediatr Infect Dis J. 2020;39(6):469. doi:10.1097/INF.0000000000002700

29. Leung CW, Kwan YW, Ko PW, et al. Severe acute respiratory syndrome among children. Pediatrics. 2004;113(6):e535-e543. doi:10.1542/peds.113.6.e535

30. Al-Tawfiq JA, Kattan RF, Memish ZA. Middle east respiratory syndrome coronavirus disease is rare in children: an update from Saudi Arabia. World J Clin Pediatr. 2016;5(4):391. doi:10.5409/wjcp.v5. i4.391

31. Letko M, Marzi A, Munster V. Functional assessment of cell entry and receptor usage for SARS-CoV-2 and other lineage B betacoronaviruses. Nat Microbiol. 2020;5(4):562-569. doi:10.1038/ s41564-020-0688-y

32. Patel AB, Verma A. COVID-19 and angiotensin-converting enzyme inhibitors and angiotensin receptor blockers: what is the evidence? JAMA. 2020;323(18):1769-1770.

33. Patel AB, Verma A. Nasal ACE2 levels and COVID-19 in children. JAMA. 2020;323(23):2386-2387. doi:10.1001/jama.2020.8946

34. Rivas-Ruiz R, Roy-García IA, Ureña-Wong KR, et al. Factors associated with death in children with COVID-19 in Mexico. Gac Med Mex. 2020;156(6):516-522.

35. Yaylacı S, Dheir H, Işsever K, et al. The effect of abo and rh blood group antigens on admission to intensive care unit and mortality in patients with COVID-19 infection. Rev Assoc Med Bras. 2020;66 (suppl 2):86-90. doi:10.1590/1806-9282.66.s2.86
Journal of Blood Medicine

\section{Publish your work in this journal}

The Journal of Blood Medicine is an international, peer-reviewed, open access, online journal publishing laboratory, experimental and clinical aspects of all aspect pertaining to blood based medicine including but not limited to: Transfusion Medicine; Blood collection, Donor issues, Transmittable diseases, and Blood banking logistics; Immunohematology; Artificial and alternative blood based therapeutics; Hematology; Biotechnology/nanotechnology of blood related medicine; Legal aspects of blood medicine; Historical perspectives. The manuscript management system is completely online and includes a very quick and fair peer-review system. Visit http://www.dovepress.com/testimonials.php to read real quotes from published authors. 